\title{
Improving Global Desirability of Apparel Design through Online Apparel Systems
}

\author{
Kanwar Varinder Pal Singh* \\ Department of Textile Technology, National Institute of Technology, GT Road Bye-Pass, Jalandhar, Punjab, India
}

Submission: September 21, 2017; Published: January 05, 2018

*Corresponding author: Kanwar Varinder Pal Singh, Department of Textile Technology, National Institute of Technology, GT Road Bye-Pass, Jalandhar, Punjab, India, Extension-3313; Tel: 0181308200; Fax: 01812690324; Email: singhkv@nitj.ac.in

\begin{abstract}
Drape is a unique property that allows a fabric to be bent in more than one direction with double curvature. For many years, researchers studied fabric drape in order to evaluate the aesthetic performance of finished garments. However, the behaviour of fabric drape may not be same as the behaviour of garment drape stand on the same object by visually observation. Such difference would affect the prediction of garment drape based on fabric drape. At present, the study of the difference between the behaviour of fabric drape and garment drape is very limited. This study aims to establish the correlation between the size and fit with comfort and handle of a garment, drape coefficient bridges the gap between virtual imaging and real product. As Overall Desirability (Do) is needed to be quantified including all the mechanical parameters of comfort and handle leading to acceptance of size and fit as per Social Desirability (Dg) leading to the formulation of Global Desirability $\left(D_{g}\right)$ i.e. $\left(D_{0} \text {. } D_{s}\right)^{1 / 2}=\operatorname{Dg}[1,2,3,4]$.

Keywords : Global desirability; 3D body scanning; Overall desirability; Social desirability
\end{abstract}

\section{Introduction}

Anthropometry is a tool to facilitate the size and fit of garment design by précising it accurately as per garment ergonomics, with either 2D or 3D body scanners. Variations in body size influence more than the nick- names given people, like "Shorty" or "Stretch." Both military and private industry frequently uses anthropometric data to assess the range of body sizes within their target populations. One of the first commercial uses for whole-body scanning is to be custom apparel design. Commonly referred to as "apparel on demand or "mass-produced custom," This process seeks to produce clothing designed and fitted to an individual's size and proportions. Shoppers use a visual product configurator, i.e. "sketchbook," to make selections including garment type, size, color, trim and accessories.

The effects of fabric mechanical properties on fabric drape and garment drape are also investigated experimentally. The drape profile, stiffness $\left(S_{d}\right.$ and $\left.S_{f}\right)$, tensile properties, thickness, and the air permeability were measured. The correlation between the parameters were calculated and reviewed. It is found that there is a high correlation of 0.97 between the actual fabric drape parameters and the 3D virtual fabric drape parameters. The outcomes of this study can improve apparel design and fabric end-use applications.

\section{Methods for System Configuration}

\section{D scanning technology}

Two primary technologies have emerged in the United States as viable candidates for surface digitizing and measurement of the human body. Both are optically based and noncontact. Laserbased scanning systems include those developed and marketed by Cyberware in Monterey, California known as Phase Measuring Profilometry (PMP) is being developed for commercialization by the Textile and Clothing Technology Corporation (TC') in Cary, North Carolina, as the front end to a custom apparel design and manufacturing system. The whole-body system built by Cyberware employs laser-scanning triangulation method to acquire 3D images.

Also pursuing the phase-stepped imaging method for human measurement is the UK Defense Clothing and Textile Agency (DCTA) in Colchester, collaborating with researchers at the National Engineering Laboratory in Glasgow, Scotland. They have developed a 3D measurement system known as AutoMate. Although technically similar to the TC2 system, its current imaging volume is only about half as large. DCTA plans a fullbody prototype of Auto-Mate for future development. The agency is also interested in custom clothing and rapid anthropometric data acquisition.

\section{Custom apparel design}

One of the first commercial uses for whole-body scanning will be custom apparel design. Commonly referred to as "apparel on demand or "mass-produced custom," this process seeks to produce clothing designed and fitted to an individual's size and proportions. While numerous obstacles confront implementation of this concept, many strong arguments support moving toward an apparel-on-demand environment: Better fitting garments, 


\section{Current Trends in Fashion Technology \& Textile Engineering}

particularly for people outside the normal size range. The process becomes extensively automated. Stock infrequently requested sizes between measurement and delivery.

Reduced cost in terms of manufacturing labor once Reduced cost in terms of overhead and no need to Rapid response, substantially reducing the time In addition to TC2's custom apparel system development, the US Defense Logistics Agency (DLA) supports collaboration between governments and industry-currently, in a program called the "Apparel Research Network'-to develop a custom-clothing system. A major goal is "custom-driven uniform manufacturing" using fast, accurate 3D measurement in the issue, design, and manufacture of military apparel. Cyber ware, along with about 20 other industry partners, is participating in this DLA-funded effort.

\section{Anthropometry/Human engineering}

Literally hundreds of anthropometric dimensions have been defined and measured for use in apparel sizing, protective equipment design, and workstation layout. The number of soft tissue and skeletal landmarks used as measurement reference points is equally staggering. For each dimension obtained in a formal anthropometric survey, there exists a precise definition and measurement procedure. The amount of time required to physically landmark people, measures them, and then record this information manually or by computer is tremendous. During the 1988 anthropometric survey of US Army personnel, researchers needed more than four hours per participant for complete data collection. The potential impact of fast and accurate imaging systems in collecting anthropometric data is clear. For that reason, researchers at the US Army Natick RD\&E Center, Soldier Systems Command, and the Armstrong Laboratory, Wright Patterson Air Force Base, researchers are examining 3D scanning systems. Armstrong Laboratory was actually the first US military group to explore laser scanners as an alternative to standard anthropometric measurement tools. Both Natick and Armstrong possess Cyber ware head/face and whole body digitizers, and seek to validate and develop reliable measurement protocols for their use. The added component of shape provided by 3D scanning offers a more detailed description of human variation. Further advantages in anthropometry and human engineering arise from the speed of data collection and the reusability of data: Once an image file is created and the necessary data extracted, it can be used again to glean additional information. In effect, the image file replaces the scanned subject, whereas the subject, once measured by traditional means, is no longer available. Once 3D whole-body data are available, a major goal for equipment design and engineering will be to define a set of representative body types or models. To do so requires using either 3D surface summarization techniques or a combination of 2D and 3D analytical methods. These 3D body forms, when integrated with commercial CAD packages, facilitate design and evaluation before prototyping. Using rapid prototyping, items designed on the computer can be produced and evaluated for fit and comfort before mass production.

\section{System design and modeling}

In addition to obtaining traditional anthropometric dimensions and 3D body shape information, a 3D scanner can also record the surface area and volume of the entire body or selected parts. A team of anthropologists and engineers at the US Army's Soldier Systems Command is currently exploiting this application in a number of ways. For example, the team, in conjunction with Beecher Research, is writing software for the Cyberware scanner to compare the degree of ballistic protection afforded a soldier wearing different designs and styles of protective body armor. This data will permit a clothing system designer to quantitatively assess total surface area coverage for a given armor type as well as the proportional distribution of total surface area at key regions of the body, such as the neck, chest, and abdomen. Also planned for development are tools for interactive design of armor (to modify the basic garment design and recompute coverage limits). The Cyberware scanner can also capture the image of a fully clothed and equipped soldier for input into computer-aided design and evaluation systems. In one application, soldiers wearing full combat gear (protective clothing, backpack, and weapon, for example) will be digitized and the resulting image files ported to a specialized software program designed to compute Infrared (IR) signature. Modeling a given clothing system's IR signature helps determine how effective the material and other design features are at minimizing soldiers' vulnerability to detection. Another project involves digitizing laser-scanned images of fully loaded paratroopers for use in computer simulations of jumps from military transport aircraft. Initially, the researchers will be working with mannequins scanned in various clothing and equipment configurations. The 3D data will be reduced and surface-meshed for input into a 3D computational fluid dynamics simulation of a paratrooper exiting the door of an aircraft.

The simulations will include the transport aircraft configuration and flow field with an integrated and moveable meshed volume around the paratrooper surface models. The paratroopers will initially be modeled as rigid volumes. Upon exit from the aircraft, a paratrooper's motion is calculated in time based on the time-dependent pressure distributed over the body surface. These 3D whole-body models will help engineers predict paratroopers' trajectory and orientation during deployment.

\section{Summing up}

Obviously, much work remains before 3D anthropometric imaging systems can be used successfully in automated apparel design and other applications requiring accurate human body size data. Further, the development of basic anthropometric data extraction tools and other related application software must be greatly enhanced regardless of the scanner type or proposed application. Still, based on current progress, the potential of 3D anthropometric imaging seems tremendous. Certainly, the costs and benefits will become more apparent with time. Probably a given method might suit some applications and not others according to variables such as data acquisition and processing 
speed, system resolution, data accuracy, and color. Technical differences aside, as long as a given system can consistently generate surface data to a known level of precision-a level acceptable for the application at hand-the system should find broad acceptance.

Finally, only careful testing and validation of new applications can ensure the long-term usefulness of any data collection system, 3D or otherwise.

\section{D Scanning Case Study}

\section{Businesses focused in improving the virtual fitting experience}

Many companies are trying to solve the high return rate problem by providing a better fit. Various technologies are being used in this field, ranging from 3D scanning, augmented reality, virtual reality, and big data. Some companies, for example, generate 3D models of apparel shoppers either from body measurements they input into a computer or from scan booths. Based on the garment size from the system database and the accurate body measurements, the computer gives recommendations or virtual tryons for the shoppers with the ease of a click of a mouse. Data-based companies, such as True Fit, collect huge database of shoppers' body sizes, preferences, and purchase histories, and are able to do big-data analysis and give recommendations. The virtual fitting industry is very crowded and competitive, regarding both its technology and operating models.

Bill Adler, CEO of True Fit, has another argument against 3D scanning: "any time you do a scan you're getting very precise measurements of the body. But we don't walk around in leotards all day." And he continues that size is not really the only factor involved: "fit, style preference, fabric, drape, all of that is really important to best outfit a person... the right piece of clothing is more than just data points on your physical body" [1]

\section{Online configuration}

It includes following phases of the study:

Phase 1: obtaining user needs and requirements

Phase 2: Development of prototypes and user tests

Phase 3: Generation of design criteria

Phase 4: Online configurator

\section{Anthropometric design criteria}

A set of linear regression equations are defined to enable to manufacture a completely custom-made garment to ensure a proper fitting [2]. (Figures 1-3).

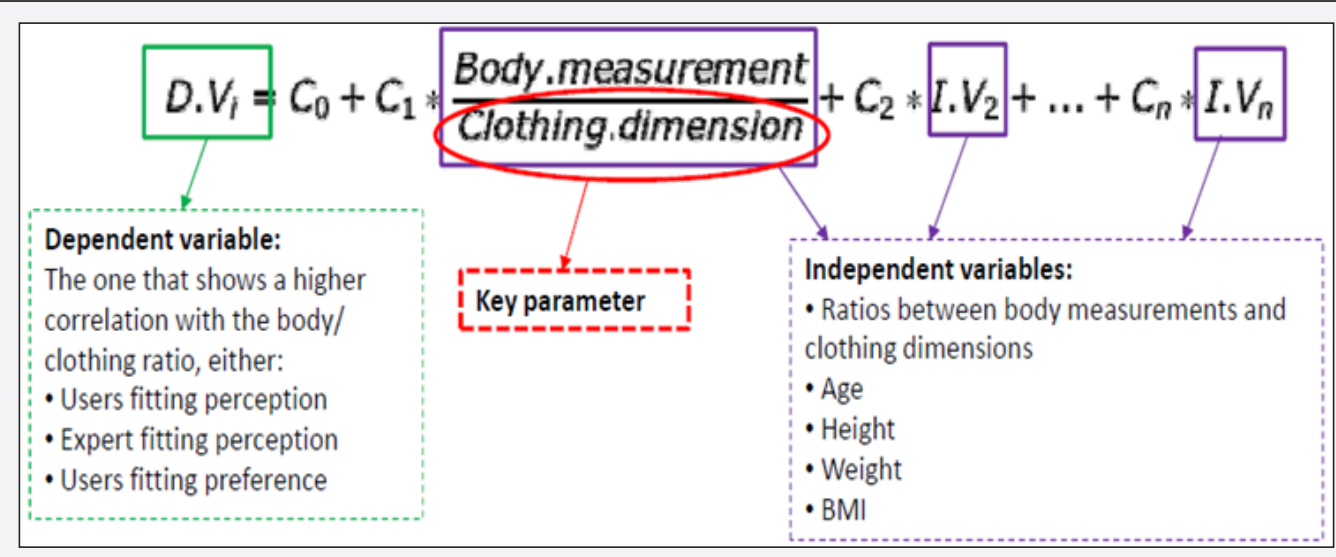

Figure 1: Linear regression Equation emphasizing Anthropometric design criteria.

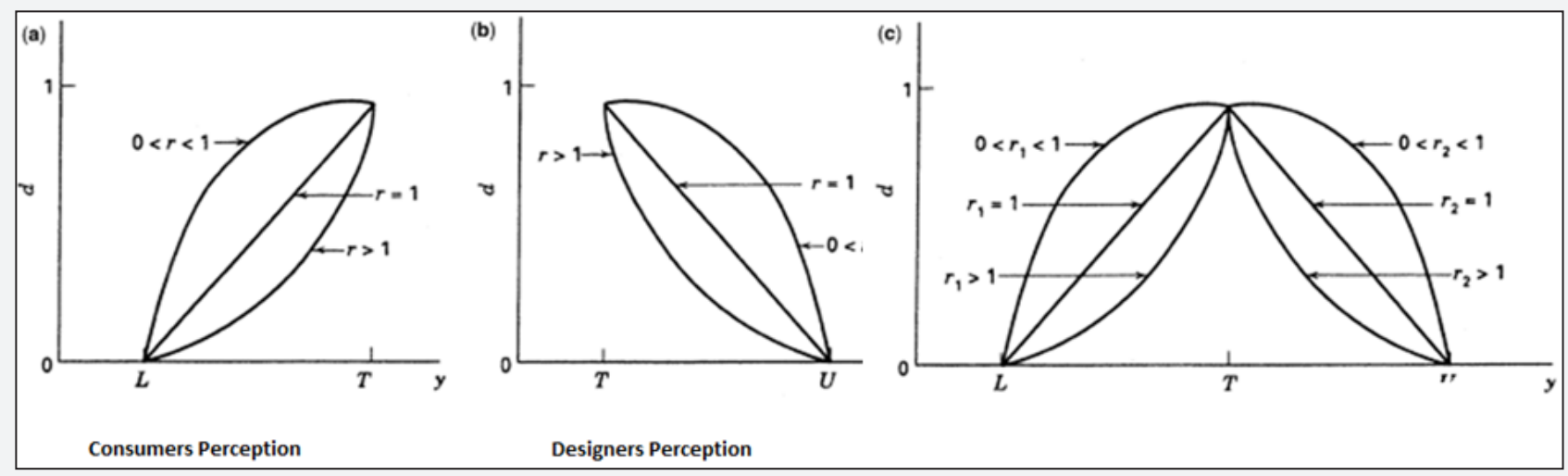

Figure 2 : Defining desired perspective of design. 


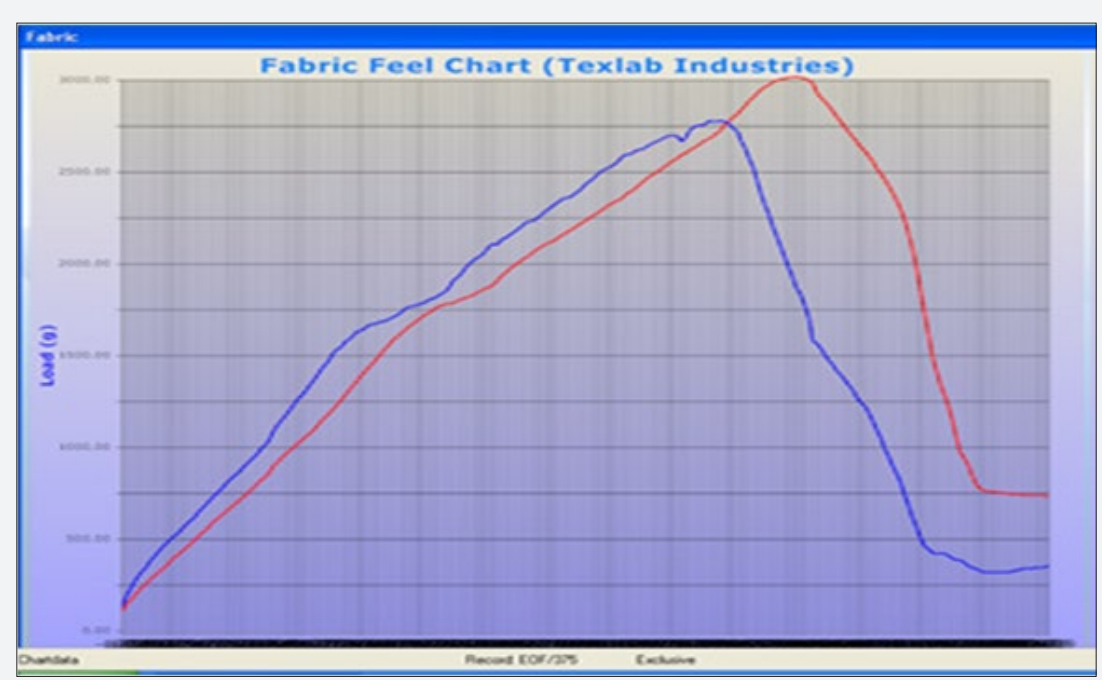

Figure 3 : Using fabric feel tester for value engineering with online configurator.

\section{Conclusion}

Design criteria with modularity through empathetic certitude of profound contemplative ecstasy is to be used to achieve the final product by concurrence of comfort, handle, and anthropometry as both offline and online through online configurator [3].

Feel Factor will provide value engineering for defining and emphasizing on garment fabric leading to derive malleability factor with anthropometry for designing through size and fit [4].

Online configurator: Beneath all technical and functional aspects, a product configuration system must fulfill, first of all, also the demands of the customer (or user) of the system. This task is of foremost importance especially if the configuration system should be used by end consumers directly, e.g. via an internet interface. The objective of this paper is to look on product configuration through the customers' eyes and present a structural approach of success factors of customer orientated product configuration with apparel data base management.

\section{Acknowledgement}

The author would like to acknowledge Department of Textile Technology, National Institute of Technology, Jalandhar, India.

\section{References}

1. Singh KVP (2017) Enhancing Feel Factor of Designed Fabric with Global Desirability of Apparel through Value Engineering. International Journal of Textile Engineering and Fashion Technology 1(3).

2. Singh KVP (2017) Semiotic Engineering (I-System) Thumb Rule to Fill the Gap between Formal Principles \& Practical Realizations of Textile, Garment \& Fashion Technology'. International Journal of Textile Engineering and Fashion Technology.

3. Singh KVP, Das A, Fanguiero R (2014) Quantification and optimization of overall desirability to achieve value added garment, International Conference on Emerging trends in Traditional \& Technical Textiles, Department of Textile Technology, NIT, Jalandhar, Punjab, India, pp. 397-399.

4. Singh KVP, Chatterjee A, Das A, Fangueiro R (2014) Anthropometric study by diagnosing and antagonizing the feel factor of 'Ideal Fabric' with 'Reference Fabric' for frugal engineering of foundation garments. Process of $5^{\text {th }}$ International Conference on 3D Body Scanning Technologies, Lugano, Switzerland, pp. 414-421.

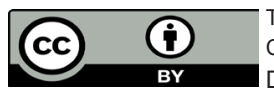

This work is licensed under Creative

Commons Attribution 4.0 Licens

DOI: 10.19080/CTFTTE.2018.01.555575

\section{Your next submission with Juniper Publishers} will reach you the below assets

- Quality Editorial service

- Swift Peer Review

- Reprints availability

- E-prints Service

- Manuscript Podcast for convenient understanding

- Global attainment for your research

- Manuscript accessibility in different formats

( Pdf, E-pub, Full Text, Audio)

- Unceasing customer service

Track the below URL for one-step submission https://juniperpublishers.com/online-submission.php 